\title{
Can Societal Impact of Scientific Work Be Measured in the Process of Re-Accreditation of Higher Education Institutions and Public Scientific Institutes in Croatia?
}

\author{
Marina Grubišić \\ Agency for Science and Higher Education, Zagreb, Croatia \\ marina.grubisic@azvo.hr \\ Sonja Špiranec \\ Faculty of Humanities and Social Sciences, University of Zagreb, Croatia \\ sspiran@ffzg.hr
}

\begin{abstract}
Summary
In this paper we present an approach to measuring the societal impact of scientific research. Our proposed methodology is based on the theory of productive interaction (Spaapen and van Drooge, 2011). The methodology was tested on the reports produced in the process of the expert evaluation of public higher education institutions (HEIs) at universities and public research institutes in Croatia. For the purpose of quantitative assessment, we have developed a conceptual framework and analyzed the narrative texts of reports based on recognising codified interactions. Finally, we discuss our results in the context of the research area of the Republic of Croatia in the fields of social sciences and biomedicine.
\end{abstract}

Key words: societal impact of scientific work, Croatian system of higher education and science

\section{Introduction}

In this paper, we review several approaches to measuring a societal impact of scientific work and propose a possible methodology for its measurement. Our proposed methodology will be assessed on a case study of the evaluation process of public higher education institutions (HEIs) at universities and public research institutes in Croatia. We will develop a conceptual framework following (Spaapen and van Drooge, 2011) which proposes evaluation based on productive interaction theory.

\section{Measuring the societal impact}

Impact assessment in the context of science is complex and challenging. Common approaches, such as citation counts, are often critiqued, while it is emphasized that traditional bibliometric indicators (Holmberg et al., 2015) do not measure impact of science on the wider community. Along with the change in funding allocation (Hicks, 2012) based on indicators, we have a strong public demand that the scientific activity should not be closed within the scientific community. Today's scientific activity is in the transition from a relatively closed system within scientific areas and fields to an open and interdisciplinary structure where knowledge creation is increasingly available to stakeholders throughout the society (Wilsdon et al., 2016). A new way of financing and a new approach to scientific, activity-emphasizing accountability to the wider community has motivated an increasing number of researchers to explore the impact of scientific work on the society at large (Benneworth, Pinheiro and Sánchez-Barrioluengo, 2016). Social impact, obviously, is an elusive concept and hard to grasp. One possible definition is that scientific work has a social impact when there is a reference to it outside the scientific community (Bornmann, Marx, 2014). Although intuitive, this definition does not imply how to demonstrate and measure, rather than presume social impact, and currently different approaches are being considered This study will contribute to the exploration of the complex concept of social impact of scientific work and possible approaches of measuring it by relying on narrative data gained in the evaluation process of HEI's in Croatia. The research is based on the framework of productive interactions, which understands productive interactions as exchanges between researchers and stakeholders in which knowledge is produced and valued that is both scientifically robust and socially relevant (Spaapen, van Drooge, 2011). 


\section{Methodological approach and research questions}

This study is based on case study data derived from experts' reports produced in the process of reaccreditation of Croatian HEIs and public research institutes. The evaluation procedure included written reports and recommendations made by expert panel indicating societal impact of scientific work. These reports are further analysed as textual material and used as a benchmark to assess the objectiveness of measurement, and thus reduce a possible bias in the results.

The study was framed by the conceptual challenge of understanding social impact in scientific work; within this broader context, research question that drive this study are:

1. Can societal impact of scientific work be measured according to the framework of productive interaction in the expert reports produced in the process of reaccreditation?

2. Are different types of institutions (faculties of public universities and public scientific institutes) putting emphasis on different types of social impact?

3. Are different scientific fields (biomedicine and social sciences) highlighting different examples of social impact?

The analysis will be was conducted by using a qualitative data processing tool (QDA Miner Lite). A document-category matrix was used in order to detect and identify instances of productive interaction in text reports. Following types of interactions where considered direct interaction (DI), indirect interaction (II) or financial interaction (FI).

The key terms for direct interaction are; participation in professional bodies and conferences, meetings with stakeholders, membership in management bodies and collaboration with public services.

The key terms for indirect interaction are; professional papers, presence in the media, social media presence and reporting to local governance.

The key terms for financial interaction are commercial and professional contracts and financing of students and teachers.

Through this qualitative analysis, we will gain an overview of the conceptual framework recognized by the expert committees as the social impact of scientific work at faculties, which are constituents of public universities, and public scientific institutes in the social and biomedical scientific field.

\section{Case study of Croatia}

In the Republic of Croatia, the social impact of scientific work has not been evaluated so far in the above-mentioned categories.

The process of re-accreditation of higher education institutions includes five phases: self-assessment of higher education institutions, visits of the expert committee to the higher education institution, preparation of the final report of the expert committee, adoption of the Accreditation Recommendation and subsequent follow-up. Each expert committee report must contain an analysis based on evidence gathered through the self-evaluation document prepared by the institution and evidence gathered during a site visit. It is equally important for the Croatian model of external evaluation that each report must have recommendations for improvement for each evaluation criterion. In addition to the above-mentioned analyses and recommendations, the expert committee also provides ratings for each evaluation criterion. In this study, final reports of expert committees for higher education in the scientific field of biomedicine and for higher education in the scientific field of social sciences were analyzed.

The research includes faculties of public universities since higher schools and polytechnics in the Republic of Croatia according to the Law on Scientific Activity and Higher Education are not obliged to carry out scientific activity or do not have to have a scientific accreditation (ASHE, 2009). In the scientific field of biomedicine, reports were analyzed for seven faculties that are part of public universities. In the scientific field of social sciences, reports were analyzed for faculties that are part of public universities that have a scientific accreditation for this area, apart from the faculties of economics. This field is not analyzed as part of the social science area because it is separately evaluated in the process of re-accreditation precisely because of its specificity. The scientific field of 
economics' societal impact is similar to the economical component of social relevance in the scientific field of technical science. In the social sciences, the reports for eighteen faculties that are part of public universities are analyzed.

The evaluation was carried out in accordance with the Criteria for assessment of quality of higher education institutions within universities (ASHE, 2013a). which were used in the 2010-2016 period.

Evaluation of public scientific institutes was carried out in accordance with the Principles and criteria for evaluation of scientific organizations in the Republic of Croatia (ASHE, 2013b). The analysis was carried out in the social science field and in the field of biomedicine sciences, so that the results are comparable with the results for higher education institutions within the public university system. Seven reports in total were analysed for four public scientific institutes in the field of social sciences and three public institutes in the field of biomedicine sciences.

Criteria from the self-evaluation report that assess the social impact of the scientific work are analyzed according to the adopted framework.

\section{Results}

All reports were analyzed according to the principle of productive interaction. A text is marked according to the number of instances when a coded interaction (grouped further in three categories) is detected in the body of text.

In the software we used, key terms are shown as categories encoded in the report texts (which are cases in this terminology). The table shows the number and percentage of codes, that is, how many times a code has appeared and what fraction (as a percentage) does it constitute of all recognized codes. The second column shows the number and the relative frequency (as a percentage) of cases, measuring in how many reports did the category appear out of the total number of reports analyzed. In both cases we restricted the number of reports by the scientific filed and the type of institution.

Table 1. Number and percentage of codes and cases - public scientific institutes in social sciences

\begin{tabular}{|l|l|l|l|l|l|}
\hline TYPE & CATEGORIES & \multicolumn{3}{|l|}{ CODES } & \multicolumn{2}{l|}{ CASES } \\
\hline DI & Professional conferences & 0 & 0 & 0 & 0 \\
\hline DI & Professional bodies & 3 & $14.30 \%$ & 3 & $75.00 \%$ \\
\hline DI & Management bodies & 1 & $4.80 \%$ & 1 & $25.00 \%$ \\
\hline DI & Meeting stakeholders & 4 & $19.00 \%$ & 4 & $100.00 \%$ \\
\hline DI & Collaboration with public services & 4 & $19.00 \%$ & 4 & $100.00 \%$ \\
\hline II & Professional publications & 0 & 0 & 0 & 0 \\
\hline II & Media presence & 2 & $9.50 \%$ & 2 & $50.00 \%$ \\
\hline II & Social media presence & 1 & $4.80 \%$ & 1 & $25.00 \%$ \\
\hline II & Reporting to local governance & 2 & $9.50 \%$ & 2 & $50.00 \%$ \\
\hline FI & Commercial contracts & 1 & $4.80 \%$ & 1 & $25.00 \%$ \\
\hline FI & Professional contracts & 3 & $14.30 \%$ & 3 & $75.00 \%$ \\
\hline FI & Financing of students & 0 & 0 & 0 & 0 \\
\hline FI & Financing of teachers & 0 & 0 & 0 & 0 \\
\hline
\end{tabular}

Table 1. shows the number and percentage of detected coded interactions and cases in the fields of social sciences.

The majority of codes for direct interaction refers to participation in meeting stakeholders and collaboration with public services in $100 \%$ of cases, the majority of codes for indirect interaction are reporting to local governance and media presence of institution participation in $50 \%$ of cases. The dominant codes for financial interaction are professional contracts in $75 \%$ of cases. 
INFuture2019: Knowledge in the Digital Age

Table 2. Number and percentage of codes and cases- faculties in public universities in social sciences

\begin{tabular}{|l|l|l|l|l|l|}
\hline TYPE & CATEGORIES & \multicolumn{2}{|l}{ CODES } & \multicolumn{2}{l}{ CASES } \\
\hline DI & Professional conferences & 2 & $2.70 \%$ & 2 & $11,10 \%$ \\
\hline DI & Professional bodies & 13 & $17.80 \%$ & 12 & $66.70 \%$ \\
\hline DI & Management bodies & 4 & $5.50 \%$ & 4 & $22.20 \%$ \\
\hline DI & Meeting stakeholders & 11 & $15.10 \%$ & 10 & $55.60 \%$ \\
\hline DI & Collaboration with public services & 3 & $4.10 \%$ & 3 & $16.70 \%$ \\
\hline II & Professional publications & 2 & $2.70 \%$ & 2 & $11.10 \%$ \\
\hline II & Media presence & 4 & $5.50 \%$ & 4 & $22.20 \%$ \\
\hline II & Social media presence & 1 & $1.40 \%$ & 1 & $5.60 \%$ \\
\hline II & Reporting to local governance & 12 & $16.40 \%$ & 12 & $66.70 \%$ \\
\hline FI & Commercial contracts & 4 & $5.50 \%$ & 4 & $22.20 \%$ \\
\hline FI & Professional contracts & 16 & $21.90 \%$ & 16 & $88.90 \%$ \\
\hline FI & Financing of students & 0 & 0 & 0 & 0 \\
\hline FI & Financing of teachers & 1 & $1.40 \%$ & 1 & $5.60 \%$ \\
\hline
\end{tabular}

Table 2. presents results for the group of faculties of public universities in the scientific fields of social sciences.

The majority of codes for direct interaction are participation in professional bodies in $66 \%$ and meeting stakeholders in 55\% of cases, the majority of codes for indirect interaction are reporting to local governance in $66 \%$ and media presence of institution in $16 \%$ of cases. The dominant codes for financial interaction are professional contracts in $88 \%$ of cases.

Table 3. Number and percentage of codes and cases - public scientific institutes in biomedicine

\begin{tabular}{|l|l|l|l|l|l|}
\hline TYPE & CATEGORIES & \multicolumn{2}{|l}{ CODES } & \multicolumn{2}{l}{ CASES } \\
\hline DI & Professional conferences & 0 & 0 & 0 & 0 \\
\hline DI & Professional bodies & 3 & $14.30 \%$ & 3 & $100.00 \%$ \\
\hline DI & Management bodies & 0 & 0 & 0 & 0 \\
\hline DI & Meeting stakeholders & 3 & $14.30 \%$ & 3 & $100.00 \%$ \\
\hline DI & Collaboration with public services & 3 & $14.30 \%$ & 3 & $100.00 \%$ \\
\hline II & Professional publications & 2 & $9.50 \%$ & 2 & $66.70 \%$ \\
\hline II & Media presence & 2 & $9.50 \%$ & 2 & $66.70 \%$ \\
\hline II & Social media presence & 1 & $4.80 \%$ & 1 & $33.30 \%$ \\
\hline II & Reporting to local governance & 4 & $19.00 \%$ & 3 & $100.00 \%$ \\
\hline FI & Commercial contracts & 2 & $9.50 \%$ & 2 & $66.70 \%$ \\
\hline FI & Professional contracts & 1 & $4.80 \%$ & 1 & $33.30 \%$ \\
\hline FI & Financing of students & 0 & 0 & 0 & 0 \\
\hline FI & Financing of teachers & 0 & 0 & 0 & 0 \\
\hline
\end{tabular}


Table 3 shows results for the group of public scientific institutes in the scientific fields of biomedicine.

All the codes for direct interaction are participation in professional bodies, meeting stakeholders and collaboration with public services in $100 \%$ of cases. The majority of codes for indirect interaction are reporting to local governance in $100 \%$ of cases, media presence, and professional publications in 66 $\%$ of cases. The dominant codes for financial interaction are commercial contracts in $66 \%$ of cases.

Table 4. Number and percentage of codes and cases - faculties in public universities in biomedicine

\begin{tabular}{|l|l|l|l|l|l|}
\hline TYPE & CATEGORIES & \multicolumn{2}{l|}{ CODES } & \multicolumn{2}{l|}{ CASES } \\
\hline DI & Professional conferences & 1 & $3.30 \%$ & 1 & $16.70 \%$ \\
\hline DI & Professional bodies & 5 & $16.70 \%$ & 5 & $83.30 \%$ \\
\hline DI & Management bodies & 1 & $3.30 \%$ & 1 & $16.70 \%$ \\
\hline DI & Meeting stakeholders & 5 & $16.70 \%$ & 5 & $83.30 \%$ \\
\hline DI & Collaboration with public services & 3 & $10.00 \%$ & 3 & $50.00 \%$ \\
\hline II & Professional publications & 3 & $10.00 \%$ & 3 & $50.00 \%$ \\
\hline II & Media presence & 0 & 0 & 0 & 0 \\
\hline II & Social media presence & 0 & 0 & 0 & 0 \\
\hline II & Reporting to local governance & 0 & 0 & 0 & 0 \\
\hline FI & Commercial contracts & 5 & $16.70 \%$ & 5 & $83.30 \%$ \\
\hline FI & Professional contracts & 5 & $16.70 \%$ & 5 & $83.30 \%$ \\
\hline FI & Financing of students & 0 & 0 & 0 & 0 \\
\hline FI & Financing of teachers & 2 & $6.70 \%$ & 2 & $33.30 \%$ \\
\hline
\end{tabular}

Table 4 indicates for the group of faculties of public universities in the scientific fields of biomedicine.

The majority of codes for direct interaction are participation in professional bodies and meeting stakeholders in $83 \%$ of cases, all the codes for indirect interaction refer to professional publications in $50 \%$. The dominant codes for financial interaction are commercial and professional contracts in $83 \%$ of cases.

\section{Conclusion}

Conceptions of impact in science are nowadays reconsidered and broadened in order to reflect the influence of scientific work on society. Societal impact is an elusive concept, which is very hard to measure, and different approaches are being examined to deal with this challenge. The aim of the study was to determine the volume of scientific results recognized by the expert committees as having societal impact for the faculties of public universities and public scientific institutes in the social and biomedical scientific field, based on the conceptual framework of productive interaction. Answer to our first question is that societal impact of scientific work can be measured according to the framework of productive interaction in the expert reports produced in the process of reaccreditation.

The results of the study indicate differences between public institutes and faculties in field of social sciences. The majority of codes for direct and indirect interaction are recognized in public institutes in the area of social sciences. The percentage of codes on faculties is smaller. Both public institutes and faculties in social sciences have recognized codes in financial interaction, especially in professional contracts. 
Similar to results in social sciences, data for public institutes and faculties in biomedicine are different. More codes for direct and indirect interaction are recognized in public institutes for biomedicine. Both public institutes and faculties in biomedicine have recognized codes in financial interaction, especially in professional contracts.

In public institutes direct and indirect interaction is more recognized than on faculties. On faculties professional bodies and professional contracts were recognized as important.

In addition to differences by type of institution (institute vs. faculty), results suggest differences in perceptions on what is recognized as social impact in different scientific fields (social sciences vs. biomedicine).

The majority of codes for direct interaction are recognized in the field of biomedicine. The percentage of codes in the field of social sciences is smaller but still relevant, especially in the case of public scientific institutes. Both fields have recognized codes in indirect interaction, but different elements were recognized as important (professional publications for biomedicine and reporting to local governance for social sciences).

Finally, both fields have recognized codes in financial interaction, and the same elements (commercial and professional contracts) were recognized as important.

The findings of the presented study highlight the potential usefulness of the concept of productive interaction as a framework for analyzing social relevance of scientific activity from narrative data, and lay groundwork for further research of differences in evaluating societal impact between different scientific fields and type of institutions.

\section{References}

ASHE. (2009). (Agency for Science and Higher Education, Act_on_Scientific_Activity). https://www.azvo.hr/images/stories/o_nama/Act_on_Scientific_Activity.pdf

ASHE. (2013a). (Agency for Science and Higher Education,Criteria for the assessment of quality of higher education institutions within universities). https://www.azvo.hr/en/evaluations/evaluations-in-higher-education/re-accreditation-ofhigher-education-institutions-2010-2016

ASHE. (2013b). (Agency for Science and Higher Education, Principles and criteria for the evaluation of scientific organisations in the republic of Croatia). https://www.azvo.hr/en/evaluations/evaluations-in-science/re-accreditation-ofscientific-organisations/re-accreditation-of-public-research-institutes

Benneworth, P., Pinheiro, R., Sánchez-Barrioluengo, M. (2016). One size does not fit all! New perspectives on the university in the social knowledge economy. // Science and Public Policy 43, 6, 731-735. doi: 10.1093/scipol/scw018

Bornmann, L., Liakata, M., Clare, A., Duma, D. (2017). Measuring scientific impact beyond academia: An assessment of existing impact metrics and proposed improvements // PLoS ONE 12, 3, 1-18. doi: 10.1371/journal.pone.0173152

Bornmann, L. (2013). What is societal impact of research and how can it be assessed? a literature survey. // Journal of the American Society for Information Science and Technology 64, 2, 217-233. doi: 10.1002/asi.22803

Bornmann, L., Marx, W. (2014). How should the societal impact of research be generated and measured? a proposal for a simple and practicable approach to allow interdisciplinary comparisons. // Scientometrics 98, 1, 211-219. doi: $10.1007 / \mathrm{s} 11192-013-1020-\mathrm{x}$

Hicks, D. (2012). Performance-based university research funding systems. // Research Policy 41, 2, 251-261. http://doi.org/10.1016/j.respol.2011.09.007

Holmberg, K., Didegah, F., Bowman, T., Kortelainet, T. (2015). Measuring the societal impact of open science Presentation of a research project. // Informaatiotutkimus, 34, 1-4, 119-123. http://search.ebscohost.com/login.aspx?direct=true\&db=llf\&AN=114559577\&site=ehost-live.

De Jong, S. P. L., van Arensbengen, P., Daemen, F., van der Meulen, B., van den Besselaar, P. (2011). Evaluation of research in context: An approach and two cases // Research Evaluation 20, 1, 61-72. doi: 10.3152/095820211X12941371876346

De Jong, S. P. L., Smit, J., Van Drooge, L. (2016). Scientists' response to societal impact policies: A policy paradox. // Science and Public Policy 43, 1, 102-114. doi: 10.1093/scipol/scv023

Samuel, G. N., Derrick, G. E. (2015) Societal impact evaluation: Exploring evaluator perceptions of the characterization of impact under the REF2014, 24, April, 229-241. doi: 10.1093/reseval/rvv007

SIAMPI et al. (n. d.). SIAMPI final report Executive summary, 1-36. doi: 10.1017/CBO9781107415324.004

Spaapen, J., Dijstelbloem, H., Wamelink, F. (2007). Evaluating research in context, A method for comprehensive assessment, 2nd edition, The Hague: COS. http://www.ericproject.n1/files.nsf/pages/NWOA_73VH8D/\$file/eric_book_internet.pdf.

Spaapen, J., van Drooge, L. (2011). Introducing "productive interactions" in social impact assessment. // Research Evaluation 20, 3, 211-218. doi: 10.3152/095820211X12941371876742 
M. Grubišić, S. Špiranec. Can Societal Impact of Scientific Work...

Wilsdon, J., Bar-Ilan, J., Frodeman, R., Lex, E., Peters, I., Wouters, P. (2016). Next-Generation Metrics: Responsible Metrics \& Evaluation for Open Science, STI 2016: Peripheries, frontiers and beyond, (September), 1-4. doi: $10.2777 / 337729$

Wilsdon, J. (2017). Responsible Metrics // Higher Education Strategy and Planning: A Professional Guide, (July), 247-254. doi: $10.13140 /$ RG.2.1.4929.1363 